TAPROBANICA, ISSN 1800-427X. April, 2011. Vol. 03, No. 01: pp. 47-48.

(C) Taprobanica Private Limited, Jl. Kuricang 18 Gd.9 No.47, Ciputat 15412, Tangerang, Indonesia.

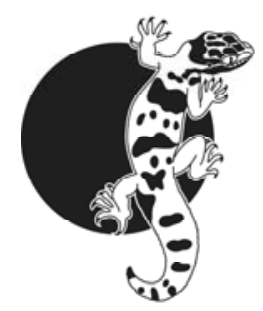

\section{Red morph of silvered lutung (Trachypithecus cristatus) rediscovered in Borneo, Malaysia}

The red morph of Silvered Lutung (Trachypithecus cristatus) a leaf monkey that reportedly occurs or occurred in northeast Borneo, has heretofore been more mythological than real. As far as I can discover, the red morph was only actually observed and reported once, by Allen \& Coolidge Jr. (1940). They recorded that seven out of fifteen adult males, but only three out of twenty-six adult females collected at Abai, were reddish. Abai is 47 miles/76 $\mathrm{km}$ from the mouth of the Kinabatangan River. This observation was repeated by others (e.g., Groves, 2001; Hooijer, 1962; Payne et al. 1985). Payne et al. (1985), who lived in Sabah, wrote that the red form occurs at the mouth of the Kinabatangan River.

In writing the species account of $T$. cristatus for Mammalian Species, Harding (2010) did not describe the red form for two reasons. First, a pale or orange form of the ebony lutung, $T$. auratus occurs in southeast Java. It was formerly classified as a subspecies, T. a. pyrrhus (Brandon-Jones et al., 2004), which is not, however, supported by genetic data (Roos et al., 2008). Nevertheless, BrandonJones et al. (2004) synonymised T. cristatus with $T$. auratus on the basis of the similarity of pelage color of some Borneo specimens of $T$. cristatus with those of T. auratus from east Java. The second reason was that the red or maroon surili (Presbytis rubicunda), another leaf monkey, occurs in Sabah where it is in some locations sympatric with $T$. cristatus (Davies, 1991). These sources of possible confusion led Harding (2010) and others to doubt whether the red form of $T$. cristatus actually existed.

On May 27, 2011, on a wildlife-watching boat ride on the middle Kinabatangan River at about $5^{\circ} 25^{\text {' }}$ $58^{\prime \prime} \mathrm{N}, 117^{\circ} 44^{\prime} 54^{\prime \prime}$ E, I saw a troop of about $20 \mathrm{~T}$. cristatus (a typical group size for this speciesAmarasinghe et al., 2009), two of which were red.
This is about 250 river $\mathrm{km}$, or 115 straight-line $\mathrm{km}$, up the river. Two smaller groups of $T$. cristatus on the Kinabatangan River and one on the Klias River in north Sabah did not have any red morphs. The local guides and boat drivers on the Kinabatangan River trip were familiar with regular occurrence of the red morph, which they referred to as "albino" silvered langurs. The said that the maroon leaf monkeys did not occur on this stretch of the Kinabatangan River, but could be found about an hour's boat drive up a nearby tributary.

One of the red ones was a sub-adult: Figure 1 shows it to have the black face of $T$. cristatus, unlike the blue-grey face of $P$. rubicunda. It also shows the pointed crest and laterally-extending cheek whiskers typical of $T$. cristatus, but unlike $P$. rubicunda.

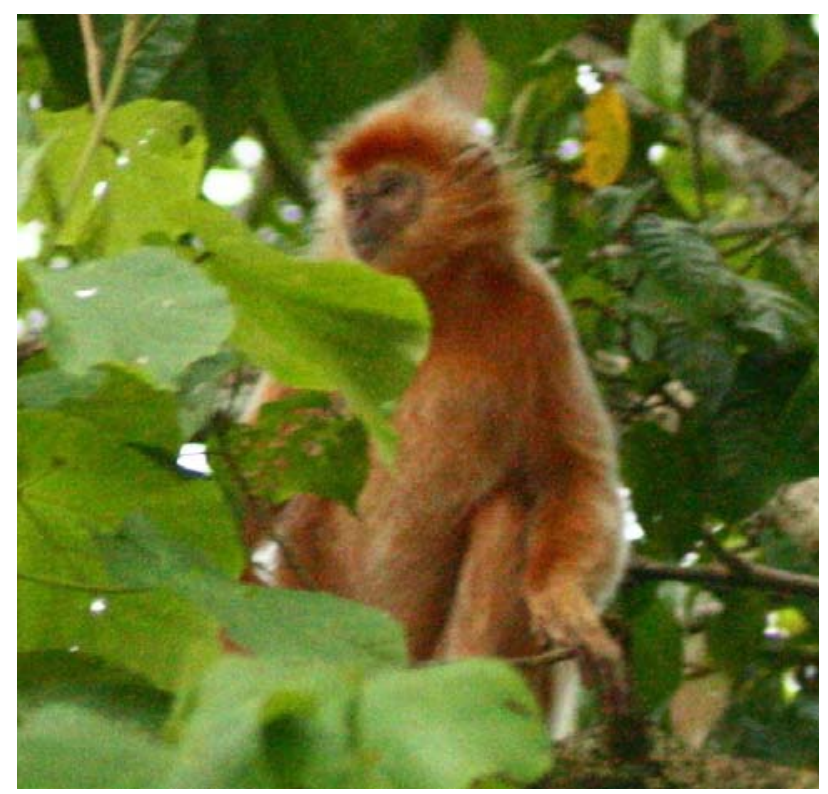

Fig. 1: A sub adult red morph of silvered lutung

Figure 2 is one of a series showing a red adult female $T$. cristatus with a black juvenile clinging to her belly. T. cristatus infants are orange and change to black adult colouration within 3-5 months (Bernstein, 1968), while $P$. rubicunda infants are whitish with black markings on the face and shoulders. Figure 3 shows a normally-coloured 
adult $T$. cristatus in the same group. These photos are grainy because of the poor evening light, but are sufficient to establish the presence of the red morph, in about the proportion originally reported by Allen \& Coolidge Jr. (1940), but considerably farther upstream on the Kinabatangan River. Hooijer (1968), citing Allen \& Coolidge Jr. (1940) called it an "erythristic mutant" and this seems the most likely explanation for the red morph.

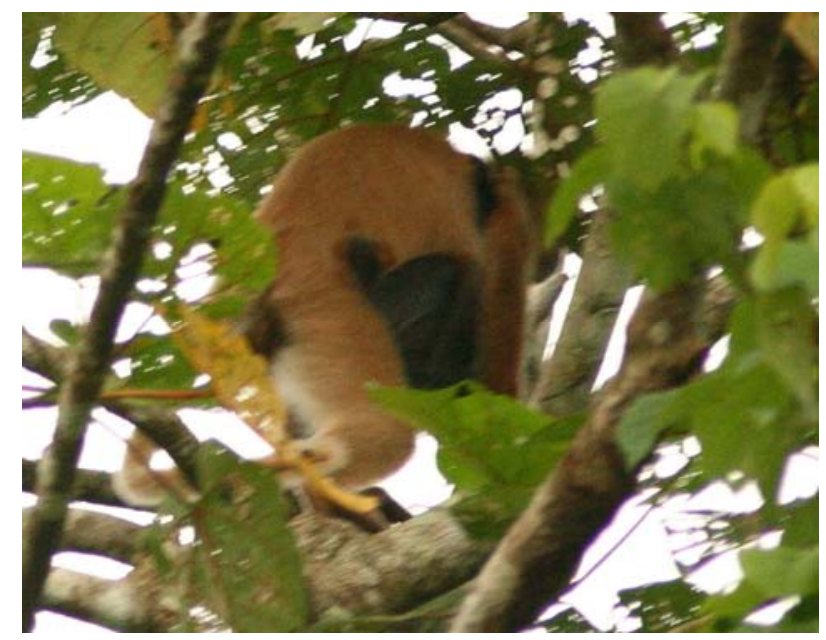

Fig. 2: An adult female red morph with a black juvenile

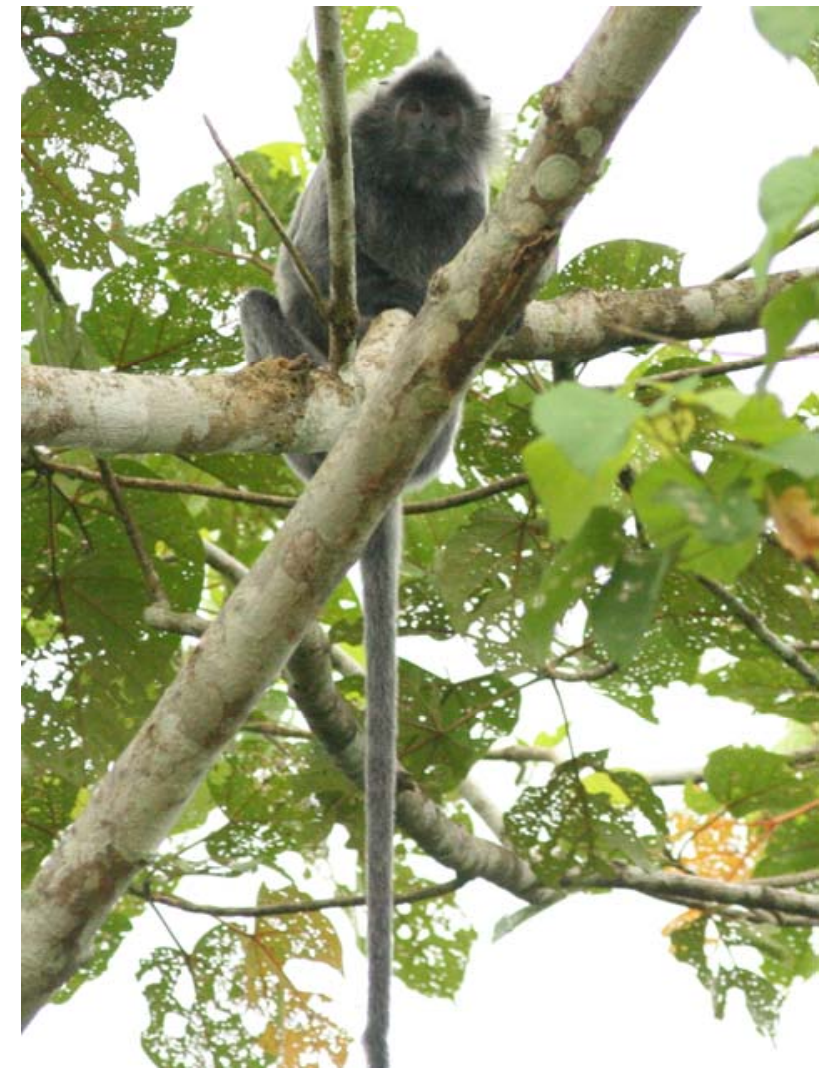

Fig. 3: a normally-coloured adult silvered lutung

\section{Literature Cited}

Allen, G. M. and H. J. Coolidge Jr., 1940. Mammal and bird collections of the Asiatic Primate Expedition. Mammals. Bulletin Museum of Comparative Zoology, 87: 131-166.

Amarasinghe, A. A. T., W. M. S. Botejue and L. E. Harding, 2009. Social behaviours of captive Trachypithecus cristatus (Mammalia: Cercopithecidae) in the National Zoological Gardens of Sri Lanka. Taprobanica, 1: 66-73.

Bernstein, I. S., 1968. The lutong of Kuala Selangor. Behaviour, 32: 1-16.

Brandon-Jones, D., A. A. Eudey, T. Geissmann, C. P. Groves, D. J. Melnick, J. C. Morales, M. Shekelle and C. B. Stewart, 2004. Asian Primate Classification. International Journal of Primatology, 25: 97-164.

Davies, G., 1991. Seed-eating by red leaf monkeys (Presbytis rubicunda) in dipterocarp forest of northern Borneo. International Journal of Primatology, 12: 119-144.

Groves, C. P., 2001. Primate taxonomy. Smithsonian Institution Press, Washington, D.C.

Harding, L. E., 2010. Trachypithecus cristatus. Mammalian Species, 42: 149-165.

Hooijer, D. A., 1962. Quaternary langurs and macaques from the Malay Archipelago. Zoolologsche Verhandelingen. 55: 3-64.

Payne, J. B., C. M. Francis and K. Phillipps, 1985. A field guide to the Mammals of Borneo. Sabah Society and World Wildlife Fund, Kuala Lumpur.

Roos, C., T. Nadler and L. Walter, 2008. Mitochondrial phylogeny, taxonomy and biogeography of the silvered langur species group (Trachypithecus cristatus). Molecular Phylogenetics and Evolution, 47: 629-636.

Submitted: 20 July 2011, Accepted: 27 July 2011

Lee E. Harding SciWrite Environmental Sciences Ltd., 2339 Sumpter Drive, Coquitlam, British Columbia, Canada E-mail: harding@sciwrite.ca 